\title{
Pengujian Keandalan Human Factors Analysis and Classification System (HFACS) Lapisan Unsafe Acts dan Unsafe Supervision Menggunakan Metode Index of Concordance
}

\author{
Iftikar Z Sutalaksana ${ }^{1}$, Tahera Kania ${ }^{2}$ \\ 12.) Fakultas Teknologi Industri, Jurusan Teknik Industri, ITB \\ Jl. Ganesa 10 Bandung 40132 \\ Email: siftikar@y7mail.com, taheraakaniaa@gmail.com
}

\begin{abstract}
ABSTRAK
Berdasarkan laporan Komite Nasional Keselamatan Transportasi(KNKT) tahun 2013, penyebab kecelakaan trans portasi udara di Indonesia 60\% diakibatkan oleh faktor manusia. Berbagai metode telah dikembangkan untuk melakukan identifikasi dan analis is human error, salah satunya adalah Human Factors Analysis and Classification System (HFACS). Metode ini menjelaskan empat tingkatan pada human failure, yaitu unsafe acts, preconditions of unsafe acts, unsafe supervision, dan organizational influences. Penelitian ini bertujuan untuk mengetahui keandalan HFACS lapisan unsafe acts dan unsafe supervision dalam menginvestigasi kecelakaan penerbangan di Indonesia serta untuk mengetahui faktor-faktor yang mempengaruhi keandalan tersebut. Metode yang digunakan dalam menguji keandalan HFACS yaitu index of concordance (IOC). Metode ini menghitung persentase kesepakatan (percentage agreement) antar responden. Sebanyak 7 orang responden terlibat dalam studi ini untuk menilai kehandalan HFACS, dengan melakukan penilaian terhadap lima kasus kecelakaan menggunakan HFACS, dan mengisi kuesioner penilaian tingkat komprehensif, fleksibilitas, efisiensi, dan kegunaan HFACS. Persentase lebih dari $70 \%$ dianggap andal. Berdasarkan hasil kuesioner, didapatkan persentase kesepakatan pada tingkat lapisan yaitu sebesar $89.50 \%$ sedangkan persentase kesepakatan pada tingkat sublapisan yaitu sebesar $24.11 \%$. Oleh karena itu, lapisan unsafe acts dan unsafe supervision andal pada tingkat lapisan namun tidak andal pada tingkat sublapisan. Terdapat beberapa faktor-faktor yang mempengaruhi keandalan ini yaitu kelengkapan informasi, responden kuesioner HFACS, petunjuk HFACS, dan prosedur penelitian.
\end{abstract}

Kata kunci: : faktor manusia, Human Factors and Classification System, keandalan, index of concordance

\section{Pendahuluan}

Kecelakaan penerbangan di Indonesia 60\% diakibatkan oleh faktor manusia [6. Besamya persentase faktor manusia ini tidak diimingi dengan investigasi terkait faktor manusia yang mendalam oleh Komite Nasional Keselamatan Transportasi (KNKT) selaku penyelidik kecelakaan transportasi. Saat ini, KNKT belum memakai metode khusus dalam menganalis is kecelakaan terkait faktor manusia. Padahal menunut Olsen \& Shomock [9], analisis kecelakaan pada industri penerbangan sangat penting dilakukan untuk terwujudnya keselamatan yang lebih baik di kemudian hari.

Salah satu metode yang dapat digunakan untuk menganalisis kecelakaan penerbangan terkait faktor manusia adalah Human Factors Analysis and Classification System (HFACS). HFACS merupakan pengembangan dari Swiss Cheese Model yang dikembangkan oleh Reason pada tahun 1990. HFACS menjelaskan empat tingkatan pada human failure, yaitu unsafe acts, preconditions of unsafe acts, unsafe supervision, dan organizational influences. Keunggulan model ini berupa taksonomi yang terorganisasi secara efisien dan terstruktur berdasarkan hierarki [1].

Berkat keunggulan yang dimiliki, HFACS telah banyak diaplikasikan untuk analisis dan klasifikasi penyebab kecelakaan pesawat terbang di berbagai negara di dunia, antara lain Amerika Serikat [14], Australia [12], Jerman[2], dan Tiongkok [8]. Selain itu, penggunaan HFACS juga tidak terbatas pada dunia penerbangan, namun juga pada kecelakaan kereta api [3], nuklir [5], dan tambang [7].

Keunggulan HFACS memberikan nilai tambah untuk diterapkan di Indonesia dalam membantu proses investigasi kecelakaan penerbangan. Namun, sebelum digunakan untuk investigasi kecelakaan, perlu dilakukan pengujian keandalan metode ini apabila digunakan pada investigasi kecelakaan penerbangan di Indonesia. Penerapan HFACS di Indonesia tentu akan berbeda dengan penerapan HFACS di Amerika Serikat, mengingat HFACS dikembangkan berdasarkan sistem penerbangan di negara tersebut. Selain itu, pemakai HFACS atau penyelidik kecelakaan juga memiliki ciri khas tersendiri, terutama karena adanya 
perbedaan budaya pada bangsa yang berbeda. Wang [12] menjelaskan bahwa apabila HFACS tidak andal untuk menginvestigasi maka perbaikan yang dilakukan berdasarkan investigasi akan menjadi salah sasaran.

Di Indonesia, lapisan unsafe acts sebagai bentuk kegagalan aktif memerlukan perhatian khusus dalam pencegahan kecelakaan . Unsafe acts merupakan lapisan yang teribat secara langsung pada kecelakaan. Selain lapisan unsafe acts, lapisan unsafe supervision sebagai salah satu kegagalan pasif juga memerlukan perhatian yang tak kalah penting. Lemahnya pengawas an yang ada di Indonesia membuat lapisan ini penting diperhatikan.

Oleh karena itu, berdasarkan perbedaan yang ada pada sistem penerbangan di Indonesia dan Amerika, diperlukan penelitian lebih lanjut mengenai keandalan HFACS terutama di lapisan unsafe acts dan unsafe supervision apabila dipakai untuk menginvestigasi kecelakaan penerbangan di Indonesia.

\section{Metode Penelitian}

Secara keselunhan, terdapat dua langkah yang dilakukan dalam studi ini, yaitu identifikasi dan klasifikasi faktor penyebab kecelakaan serta penilaian keandalan HFACS dalam menginvestigasi kecelakaan. Faktor penyebab kecelakaan dikumpulkan dari laporan-laporan kecelakaan yang dikeluarkan oleh KNKT. Faktor ini kemudian diklasifikasikan berdasarkan taksonomi HFACS. Hasil klasifikasi diuji keandalannya dengan memberikan kuesioner kepada ahli.

\subsection{Respoden Kuesioner Keandalan}

Responden kuesioner ini sesuai dengan target pengguna HFACS, yaitu praktisi pada bidang keselamatan penerbangan [12]. Jumlah responden pada penelitian ini yaitu tujuh orang penyelidik kecelakaan dengan latar belakang keilmuan penerbangan.

\subsection{Identifikasi Faktor Penyebab Kecelakaan}

Terdapat beberapa langkah yang dilakukan untuk mengindentifikasi dan mengklasifikasi faktor penyebab kecelakaan menggunakan metode HFACS.

1. Membaca laporan KNKT, dilakukan untuk mengetahui informasi-informasi terkait kecelakaan yang terjadi. Informasi tersebut mencakup kronologis kecelakaan, lokasi kecelakaan, data petugas penerbangan yang terlibat, temuan-temuan penyelidik terkait kecelakaan, dan terakhir, analisis penyebab kecelakaan. Total laporan yang dikumpulkan adalah sebanyak 46 laporan final kecelakaan yang didapatkan dari hasil investigasi oleh Komite Nasional Keselamatan Transportasi (KNKT) dari tahun 2009-2013.

2. Mengidentifikasi faktor-faktor penyebab kecelakaan dari pembahasan dalam laporan KNKT

3. Mengklasifikasikan faktor-faktor penyebab kecelakaan ke dalam taksonomi HFACS. Setiap kategori yang ada di dalam taksonomi HFACS harus dipahami agar tidak terjadi kesalahan dalam klasifikasi. Pengklasifikasian faktor menggunakan kode-kode HFACS yang diambil dari Jambak [4].

4. Membuat rangkuman hasil klasifikasi berdasarkan lapisan dan sublapisan HFACS yang menjadi faktor penyebab kecelakaan

\subsection{Perhitungan Keandalan HFACS}

Penilaian keandalan HFACS dalam investigasi kecelakaan penerbangan di Indonesia dilakukan dengan menyebarkan kuesioner kepada penyelidik-penyelidik kecelakaan yang telah berpengalaman di dunia penerbangan. Kuesioner berisi faktor-faktor penyebab suatu kecelakaan terkait human factor. Kemudian para responden memilih kode HFACS pada lapisan unsafe acts dan unsafe supervision yang sesuai dengan faktorfaktor yang telah disebutkan untuk kasus kecelakaan yang diberikan.

Sebanyak lima kecelakaan yang dikaji dalam kuesioner penelitian ini. Kelima kecelakaan ini dipilih karena memiliki faktor manusia yang banyak. Masing-masing bagian kecelakaan berisi faktor-faktor penyebab terkait faktor manusia dan isian kode yang harus diisi oleh responden.

Selain kuesioner kecelakaan, kuesioner singkat yang diambil dari Olsen dan Shorrock [9] juga diberikan. Kuesioner ini bertujuan untuk mengetahui tingkat komprehensif, fleksibilitas, efisiensi, dan kegunaan HFACS yang dirasakan oleh responden. 
Sebelum responden mengisi kuesioner, diberikan perkenalan dan pelatihan meng gunakan HFACS terlebih dahulu. Perkenalan dan pelatihan ini dilakukan agar responden mengerti HFACS secara mendalam dan mampu menggunakannya dengan benar. Isian kode dalam kuesioner diisi dengan kode yang menurut responden paling sesuai dengan faktor temuan manusia yang diberikan. Petunjuk pengkodean HFACS juga diberikan agar responden mudah mengisi kuesioner.

Dalam pengisian kuesioner Olsen \& Shorrock [9], responden diminta untuk memberikan nilai terkait pernyataan yang disajikan. Skala yang disajikan yaitu dari 1 (sangat tidak setuju)hingga 5 (sangat setuju).

\subsection{Metode Analisis Keandalan HFACS}

Metode Index of Concordance digunakan untuk mengetahui tingkat keandalan HFACS. Cara ini dipilih karena menurut Martin dan Bateson (1993) dalam Ross et al. [10] metode yang cocok untuk menghitung kesepakatan antar penilai adalah dengan index of concordance.

Rumus untuk menghitung persentase kesepakatan yaitu:

$$
\text { Persentase kesepakatan }=\frac{\text { jumlah sepakat }}{\text { jumlah pasangan }} \times 100 \%
$$

Dengan menghitung kesepakatan antar penilai, dapat diketahui keandalan HFACS pada lapis an unsafe acts dan unsafe supervision beserta sublapis an di dalamnya. Sebagai petunjuk tingkat keandalan HFACS, Borg dan Gall (1989) dalam Wallace dan Ross [11] menyatakan bahwa dalam studi penelitian, tingkat 70\% disetujui sebagai dapat diterima (acceptable). Oleh karena itu, persentase kesepakatan diatas $70 \%$ antar penilai dinilai andal.

\section{Hasil}

\subsection{Identifikasi Faktor Penyebab Kecelakaan}

HFACS mengidentifikasi penyebab-penyebab kecelakaan terkait human factor dengan empat lapisan yaitu unsafe acts, preconditions of unsafe acts, unsafe supervision, dan organizational influences. Hasil yang didapatkan dari klasifikasi faktor penyebab kecelakaan terkait human error pada laporan KNKT yang telah di identifikasi ditunjukkan pada Gambar 1.

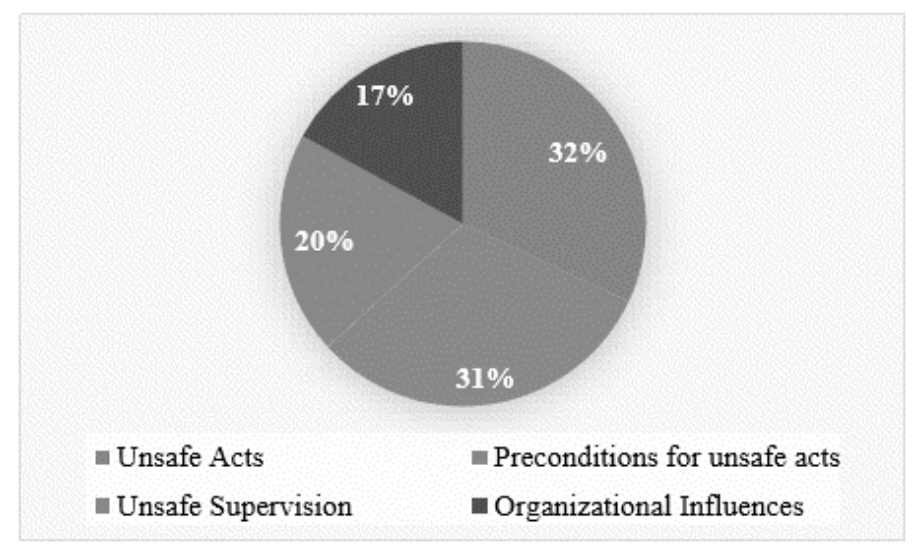

Gambar 1 Hasil Klasifikasi Faktor Penyebab Kecelakaan Indonesia dari Laporan KNKT 2009-2013

Lapisan HFACS yang paling sering muncul pada kecelakaan penerbangan yang diteliti yaitu lapisan unsafe acts dengan persentase sebesar 32\%. Lapisan ini tidak jauh berbeda dengan kemunculan lapisan precondition for unsafe acts dengan persentase sebesar 31\%. Lapisan unsafe supervision muncul dengan persentase sebesar $20 \%$. Terakhir yaitu lapisan organizational influences, lapisan ini muncul dengan persentase sebesar $17 \%$.

\subsection{Perhitungan Keandalan HFACS}

Tabel 1 menunjukkan persentase kesepakatan pada tingkat lapisan dan sublapisan. Pada tingkat sublapisan, persentase kesepakatan yang didapatkan sangat kecil yaitu 24.11\%. Pada tingkat lapisan, persentase kesepakatan yang didapatkan besar yaitu 89.5\%. Tabel 2 menunjukkan hasil kuesioner Olsen \& Shorrock [9]. 
Tabel 1 Persentase Kesepakatan Tingkat Lapisan dan Sublapisan

\begin{tabular}{cccccc}
\hline \multirow{2}{*}{ No } & \multirow{2}{*}{ Registrasi Pesawat } & \multicolumn{2}{c}{ Lapisan } & \multicolumn{2}{c}{ Sublapisan } \\
\cline { 2 - 6 } & Jumlah Sepakat & Jumlah Pasangan & Jumlah Sepakat & Jumlah Pasangan \\
\hline 1 & PK-BRD & 170 & 183 & 52 & 183 \\
2 & PK-CKM & 113 & 119 & 23 & 119 \\
3 & PK-MZK & 166 & 191 & 49 & 191 \\
4 & 97004 & 93 & 106 & 26 & 106 \\
5 & PK-CLJ & 63 & 77 & 13 & 77 \\
\hline \multicolumn{2}{r}{ Persentase Kesepakatan } & 605 & 676 & 163 & 676 \\
\hline
\end{tabular}

Tabel 2 Hasil Kuesioner Olsen dan Shorrock [9]

\begin{tabular}{|c|c|c|}
\hline No & Pernyataan & Median \\
\hline 1 & $\begin{array}{l}\text { I am confident that other HFACS users would assign the same contributing } \\
\text { factors as me given the same evidence }\end{array}$ & Setuju \\
\hline 2 & The definitions and explanations provided were sufficient and clear & Setuju \\
\hline 3 & The classification system was easy to use & Setuju \\
\hline 4 & $\begin{array}{l}\text { I was able to suitably assign contributing factors with my current level of } \\
\text { training }\end{array}$ & Setuju \\
\hline 5 & $\begin{array}{l}\text { After analysing the incident and assigning contributing factors, I can easily } \\
\text { see error reduction or mitigation measures }\end{array}$ & Setuju \\
\hline 6 & $\begin{array}{l}\text { Had I known more information about the incident or were more } \\
\text { experienced, I would have been more able to assign contributing factors }\end{array}$ & Setuju \\
\hline 7 & The codes could be applied specifically to the airlines environment & Setuju \\
\hline 8 & $\begin{array}{l}\text { The classification system provides a logical breakdown for human } \\
\text { performance errors }\end{array}$ & Setuju \\
\hline 9 & The categories were sufficient to cover all of the necessary factors & Setuju \\
\hline
\end{tabular}

\section{Analisis}

Berdasarkan identifikasi faktor penyebab kecelakaan dengan HFACS, dari 46 kecelakaan, faktor manusia teribat sebagai salah satu penyebab kecelakaan pada 38 kecelakaan. Dengan kata lain, faktor manusia menyumbang $82.6 \%$ pada kecelakaan penerbangan periode 2009-2013.

Persentase hasil identifikasi tersebut tidak jauh berbeda dengan penelitian yang dilakukan oleh Shappell dan Wiegmann (1996) dalam [13] yang menyebutkan bahwa antara $70-80 \%$ penyebab kecelakaan pesawat adalah human error. Data lainnya yaitu data investigasi KNKT pada tahun 2013 menjelaskan bahwa penyebab kecelakaan transportasi udara di Indonesia pada tahun 2007-2013 yaitu sebesar 60\% diakibatkan oleh faktor manusia. Perbedaan persentase sebesar 22.6\% bukanlah perbedaan yang sedikit. Walaupun penelitian ini tidak menganalis is kecelakaan pada tahun 2007 dan 2008, nampaknya HFACS menjabarkan faktor manusia dengan lebih lengkap. Selain itu, kecilnya persentase yang dihasilkan oleh KNKT juga dipenganuhi oleh tidak adanya framework khusus yang digunakan oleh KNKT dalam menginvestigasi human factor dalam suatu kecelakaan.

Berdasarkan hasil kuesioner HFACS, persentase kesepakatan tingkat lapisan yaitu sebesar 89.50\% sedangkan pada tingkat sublapis an yaitu sebes ar $24.11 \%$. Persentase tersebut menunjukkan bahwa HFACS andal pada tingkat lapisan namun tidak andal pada tingkat sublapisan. Hal ini dikarenakan persentase kesepakatan yang dicapai pada tingkat lapisan lebih dari $70 \%$ dan persentase kesepakatan pada tingkat sublapisan kurang dari $70 \%$.

Keandalan pada tingkat lapisan dapat dicapai karena penyelidik-penyelidik kecelakaan penerbangan di KNKT telah menggunakan Swiss Cheese Model dalam menginvestigasi kecelakaan terkait faktor manusia. Penggunaan Swiss Cheese Model ini telah membuat para responden yang merupakan penyelidik kecelakaan di KNKT membedakan satu lapisan dengan lapisan lainnya dengan mudah.

Sedangkan keandalan pada tingkat sublapisan tidak dapat dicapai karena responden kuesioner tidak mengetahui HFACS sebelumnya atau sebatas pernah mendengar metode ini. Penjelasan dan pelatihan mengklasifikasi faktor manusia dengan HFACS secara ringkas tidak cukup untuk menghasilkan sublapisan HFACS yang andal.

Selain pengetahuan responden tentang Swiss Cheese Model dan HFACS terdapat beberapa faktor lainnya yang mempengaruhi keandalan HFACS lapisan unsafe acts dan unsafe supervision baik di tingkat lapisan maupun 
sublapisan. Faktor yang pertama yaitu kelengkapan informasi. Lenné et al. [7] menyebutkan bahwa pendekatan seperti HFACS sangat tergantung pada data yang dimiliki dan kemampuan analis. Semakin lengkap informas $i$ yang dimiliki maka proses identifikasi dan klasifikasi HFACS akan lebih jelas. Hal yang serupa juga berlaku pada kemampuan analis, semakin dalam pemahaman analis terhadap satu kecelakaan maka identifikasi dan klasifikasi HFACS akan lebih jelas dan mudah.

Keterbatasan informasi yang didapat oleh KNKT salah satunya diakibatkan oleh tidak adanya data primer pada investigasi kecelakaan. Sebagai contoh yaitu pada kecelakaan registrasi pesawat PK-BRD, kru pesawat tidak merespon peringatan suara. Alasan mengabaikan peringatan suara ini tidak diketahui. Sehingga dalam memberikan kode, responden meras a tidak yakin.

Selain itu, tidak seluruh responden pada penelitian ini terjun langsung pada investigasi kecelakaan yang ada pada kuesioner. Hal ini mengakibatkan adanya perbedaan pemahaman mengenai kecelakaan antara satu responden dengan responden yang lain.

Faktor yang kedua yaitu responden kuesioner HFACS. Target pengguna HFACS adalah praktisi pada bidang keselamatan penerbangan [7]. Terdapat beberapa penelitian yang menguji keandalan HFACS tidak menggunakan target pengguna HFACS yang sesungguhnya, seperti ahli human factor maupun psikolog. Tidak sesuainya responden dengan target pengguna HFACS mampu mengurang i keakuratan hasil penelitian [12].

Responden kuesioner pada penelitian ini sudah sesuai dengan target pengguna HFACS. Namun, kekurangan pada penelitian ini yaitu kurang beragamnya latar belakang keilmuan para responden. Hampir seluruh responden berasal dari dunia penerbangan, baik penerbang, teknisi, maupun ATC (Air Traffic Controller). Padahal dalam suatu tim investigasi kecelakaan, selain ahli penerbangan, penyelidik kecelakaan jug a terdiri dari berbagai latar belakang keilmuan seperti dokter, ahli human factor, dan psikolog. Beragamnya latar belakang keilmuan responden akan memberikan hasil yang lebih merepresentasikan penerapan HFACS di dunia nyata.

Pengetahuan serta pengalaman responden menggunakan metode HFACS juga mempengaruhi keandalan. Semakin dalam pengetahuan dan semakin sering responden menggunakan metode ini maka persentase kesepakatan yang dihasilkan antar responden juga akan meningkat. Hal ini diperkuat dengan tingginya persentase kesepakatan pada tingkat lapisan. Lapisan-lapisan dalam HFACS sama dengan lapisan-lapisan dalam Swiss Cheese Model. Seluruh responden pada penelitian ini telah mengetahui dan memahami Swiss Cheese Model dengan baik sehingga dapat membedakan faktor manusia pada tiap lapisan dengan baik. Hal yang sebaliknya terjadi pada tingkat sublapisan. Rendahnya persentase kesepakatan pada tingkat ini dapat dipengaruhi oleh pengetahuan responden tentang HFACS yang masih kurang. Sebagian besar responden tidak mengetahui HFACS sebelumnya dan seluruh responden baru sekali memakai pengklasifikasian HFACS.

Faktor ketiga adalah petunjuk HFACS. Wang et al. [12] menyatakan bahwa pada tingkat sublapisan, banyak sublapis an yang mirip satu sama lain. Kemiripan sublapisan s atu sama lain akan mengurangi kesepakatan karena penilai akan merasa kesulitan memilih kode yang tepat. Sebagai contoh yaitu sublapisan leadership/supervison/oversight inadequate (kondisi kepemimpinan, pengawasan yang tidak memadai) dan supervision - modelling (pengawas an - panutan). Keduanya di bawah lapisan unsafe supervision dan menjelaskan bahwa faktor yang menyebabkan kecelakaan saat kualitas pemimpin atau pengawas tidak baik.

Petunjuk pengkodean HFACS diambil dari penelitian Jambak [4]. Terdapat beberapa kekurangan dalam petunjuk pengkodean ini. Pertama, penerjemahan Bahasa Inggris ke Bahasa Indonesia yang kurang tepat. Terdapat perbedaan arti antara istilah yang dipakai pada pengkodean dan penjelas annya.

Kekurangan lainnya yaitu penggunaan kata aman dan selamat sering kali disamakan. Menurut Kamus Besar Bahasa Indonesia, arti kata aman adalah bebas dari bahaya. Sedangkan arti kata selamat adalah terbebas dari bahaya, malapetaka, bencana; terhindar dari bahaya, malapetaka; bencana; tidak kurang suatu ap a; tidak mendapat gangguan; kerusakan, dsb. Walaupun tampak mirip, penggunaan kedua kata ini harus diperhatikan dan dibedakan.

Faktor yang terakhir adalah prosedur penelitian. Menurut Wallace et al. (2004) dalam Wang et al. [12], faktor penyebab kecelakaan yang telah diidentifikasi sebelumnya kemudian dikodekan oleh responden akan meningkatkan keandalan sebesar 20\% dibandingkan dengan responden mengidentifikasikan faktor manusia secara individu. Hal ini dikarenakan oleh adanya kemungkinan tiap responden memberikan jumlah faktor manusia yang berbeda sehingga menurunkan persentase kesepakatan. 
Pada penelitian ini faktor manusia pada kecelakaan telah diidentifikasi sehingga responden langsung memberikan kode HFACS yang paling sesuai dengan pernyataan yang ada di kuesioner. Dengan demikian peningkatan keandalan sebesar $20 \%$ sudah termasuk dalam perhitungan persentase keandalan yang dihitung.

Dalam menghitung persentase kesepakatan, penelitian ini menggunakan metode index of concordance. Metode ini lebih tepat digunakan dibandingkan dengan metode Cohen Kappa karena kondisi untuk menggunakan Cohen Kappa tidak terpenuhi.

Pengolahan kuesioner Olsen \& Shorrock [9] memberikan hasil bahwa terdapat beberapa pernyataan yang mendukung dan terdapat pula pernyataan yang bertolak belakang dengan hasil keandalan HFACS dan faktorfaktor yang mempengaruhinya. Pernyataan yang mendukung hasil keandalan HFACS dan faktor-faktor yang mempengaruhinya yaitu pernyataan nomor enam. Pernyataan yang bertolak belakang yaitu pernyataan nomor satu, dua, empat, dan sembilan.

Beberapa hal yang mempengaruhi hasil kuesioner ini mendukung maupun menolak hasil kuesioner keandalan HFACS dan faktor-faktor yang mempengaruhinya yang pertama, yaitu rasa percaya diri yang tinggi pada responden. Responden penelitian ini telah berkecimpung dalam dunia investigasi penerbangan dalam jangka waktu yang cukup lama. Oleh karena pengalaman mereka yang tinggi, maka wajar apabila timbul rasa percaya diri pada responden. Selain itu, terdapat kemungkinan responden salah mengisi kuesioner. Skala yang disajikan yaitu dari satu (sangat tidak setuju) hingga lima (sangat setuju). Tidak menutup kemungkinan bahwa terdapat responden yang terbalik memberikan nilai pada pernyataan-pernyataan di kuesioner ini.

\section{Kesimpulan dan Saran}

Lapisan unsafe acts dan unsafe supervision andal pada tingkat lapisan dengan persentase kesepakatan yang terjadi antara para responden yaitu sebesar $89.50 \%$. Namun, hasil sebaliknya didapatkan pada tingkat sublapisan dengan persentase kesepakatan sebesar $24.11 \%$. Faktor-faktor yang mempenganuhi keandalan HFACS, yaitu kelengkapan informasi, responden kuesioner HFACS, petunjuk HFACS, dan prosedur penelitian.

\section{Referensi}

[1] Beaubien, J. M. \& Baker, D. P., A Review of Selected Aviation Human Factors Taxonomies, Accident/Incident Reporting Systems, and Data Reporting Tools, International Journal of Applied Aviation Studies, 2(2), hal. 11-36, 2002.

[2] Dambier, M., Hinkelbein, J. (2006). Analysis of 2004 German General Aviation Aircraft Accidents According to the HFACS Model. Air Medical Journal, 25(6), 265-269.

[3] Izazaya, E. (2012). Kajian Taksonomi Kecelakaan Kereta Api di Indonesia Menggunakan Human Factors Analysis and Classification System (HFACS). Tesis Institut Teknologi Bandung.

[4] Jambak, M. I., Perancangan Petunjuk Pelaksanaan Penyelidikan Faktor Manusia pada Kecelakaan Pesawat Udara Sipil di Indonesia. Teknik dan Manajemen Industri, Institut Teknologi Bandung, Bandung, 2011.

[5] Kim, S. K., Jang, T. I., Lee, Y. H., Shin, K. H. (2012). Investigations on Human Error Hazards in Recent Unintended Trip Events of Korean Nuclear Power Plants. Transactions of the Korean Nuclear Society Autumn Meeting, (pp. 2526). Korea.

[6] Komisi Nasional Keselamatan Transportasi, Accident Reports, NTSC Aviation, http://www.dephub.go.id/knkt/ntsc aviation/aaic.htm, (1 Mei 2014).

[7] Lenné, M. G., Salmon, P. M., Liu, C. C. \& Trotter, M., A Systems Approach to Accident Causation in Mining: An Application of the HFACS Method, Accident Analys is and Prevention, xxx, hal. xxx-xxx, 2011.

[8] Li, W. C., Harris, D., Yu, C. S. (2008). Routes to Failure: Analys is of 41Civil Aviation Accidents From the Republic of China Using The Human Factors Analysis and Classification System. Accident Analysis and Prevention, 40, 426-434.

[9] Olsen, N. S. \& Shorrock, S. T., Evaluation of the HFACS-ADF Safety Classification System: Inter-Coder Consensus and Intra-Coder Consistency, Accident Analysis and Prevention, 42, hal. 437-444, 2010.

[10] Ross, A. J., Wallace, B. \& Davies, J. B., Technical Note: Measurement Issues in Taxonomic Reliability, Safety Sciences, 42, hal. 771-778, 2004.

[11] Wallace, B. \& Ross, A., Beyond Human Error, CRC Press, 80-86, 2006. 
[12] Wang, L., Wang, Y., Yang, X., Cheng, K., Yang, H., Zhu, B., . . Ji, X, Coding ATC Incident Data Using HFACS: Intercoder Consensus, International Journal of Quality, Statistics, and Reliability, 2011, hal. 1-8, 2011.

[13] Shappell, S. A., Wiegmann, D. A. (2001). Applying Reason: The Human Factors Analysis and Classification System(HFACS). Human Factors and Aerospace Safety, 1, 59-86

[14] Wiegmann, D. A., Shappell, S. A. (2001). Human Error Perspective in Aviation. The International Journal of Aviation Psychology, 11(4), 341-357 